\title{
Ética y Valores 1
}

Crispín Günter Stücker*

cstücker@lasallep.edu.mx

Martín López Calva y Lorena Barquín García-Villoslada

Trillas, 2007

Desde el año 2004 la Dirección de Bachillerato de la SEP viene introduciendo la asignatura de "Ética y Valores" para el plan de estudios del primer año de la educación media superior. En atención a la propuesta programática de esta asignatura, Martín López Calva y Lorena Barquín García-Villoslada acaban de publicar un curso a través de la Editorial Trillas. Un libro de 156 páginas que invita a un viaje de exploración para descubrir el "código humano" (o "código H"). Desde su visión humanista traducen el objetivo técnico del programa oficial1 en una proyección dinámica de estudio y reflexión: "Este curso es una invitación a descubrir las claves de traducción y aplicación de este código, no solamente en el nivel teórico-conceptual... sino en el nivel existencial" (pag. 9), a fin de "leernos como sujetos humanos en el mundo real; construirnos una vida humana y hacer más humanamente vivible el mundo".

Los 6 capítulos del libro articulan los temas centrales que marca el programa oficial:

- bajo el seudónimo de "Clave E": la ética;

- con la "Clave L": la libertad;

- la democracia y los derechos humanos en la "Clave D";

- la globalización y multiculturalidad en el capítulo correspondiente a la "Clave M";

- con la "Clave CT" los temas de ciencia y tecnología;

- y para finalizar la "Clave S" como sinónimo de desarrollo sustentable.

En el capítulo final los autores ofrecen una "integración del código H" como conclusión y trabajo integrador. La cita que sigue documenta el nivel de reflexión que pretenden propiciar:

"Todo esto unido puede y debe dar como resultado la construcción progresiva de sociedades sustentables, es decir, sociedades que no pierdan la mirada ética 
(clave E) para construir por medio de un proceso democrático y de respeto a los derechos humanos fundamentales (clave $D$ ), usando como herramientas clave la ciencia y la tecnología al servicio de la humanización (clave CT) que respeta la multiculturalidad y construye interculturalidad (clave M), para ir avanzando hacia el proyecto de libertad al que la humanidad está llamada como sujeto activo (clave $L$ ) (pag. 150).

1 "El estudiante: Planteará problemas y soluciones en los ámbitos de decisión personal y social, de la diversidad cultural, el desarrollo de la ciencia y la tecnología, y el mejoramiento de la relación sociedad-naturaleza, mediante el análisis y la reflexión sustentados en información objetiva, mostrando actitudes de responsabilidad, respeto y tolerancia."

Para cada una de las seis claves temáticas, los autores ofrecen una gama amplia de ejercicios de reflexión; tanto para articular y compartir la experiencia estudiantil como para profundizar los planteamientos teóricos. Su opción enfática hacia el lector alumno radica en, "acompañarte en un proceso de análisis crítico y adopción responsable de una ética personal que sea aplicable en un mundo complejo, plural, dinámico, incierto y heterogéneo" (pag. 27), "desde una opción clara por una ética de la realización personal y colectiva y no a partir de una ética de la ley; desde una ética del querer humanizante y no desde una ética del deber moralizante" (pag. 28).

Con el presente libro Martín López y Lorena Barquín ofrecen una aplicación creativa y dinámica al reto educativo que significa el programa de "Ética y Valores". Al introducir los términos de "código" y "clave" rompen la estructura técnica de la propuesta oficial. Quienes compartimos la preocupación por lo profundamente humano y por una convivencia humanizante entre los seres humanos, nos encantamos con el planteamiento de los temas y dinámicas de reflexión y sensibilización. Sin embargo me pregunto si este libro como herramienta para alumnos y alumnas permite lograr el objetivo del curso, mismo que los autores definen como un "proceso de estudio y reflexión ciertamente intelectual, pero también y sobre todo existencial, de elementos, preguntas, ideas, temas o problemas que nos capaciten en forma progresiva para aprender a vivir mejor" (pag. 22).

Dudo que este curso pueda realizarse con jóvenes de bachillerato tal como los autores lo prevén. Sobre todo los largos y complejos textos de exposición temática me parecen demasiado exigentes; los objetivos de "análisis crítico y adopción responsable de una ética personal que sea aplicable en un mundo complejo", demasiado ambiciosos para las realidades que los jóvenes comúnmente vienen trayendo al inicio de sus estudios de bachillerato. Aunque los ejercicios propuestos 
para cada tema y capítulo corresponden a los niveles que en títulos similares para la formación ética en bachillerato se manejan, las reflexiones antropológicas y éticas se articulan a niveles de personas con fundamentos para la reflexión ética humanista.

Es desde estas observaciones y apreciaciones que recomiendo hacer uso de este libro no tanto para las clases, sino más bien para la capacitación y actualización de docentes de la asignatura de "Ética y Valores". Su lectura y la realización de los ejercicios que propone, fomentarán, sin duda alguna, una mayor claridad por la noción de lo "humano" y de lo ético. Los autores nos retan a superar el aprendizaje memorístico de las materias formativas y llegar a articular con profundidad y amplitud los aspectos clave de una vida humana plena - sensibles por las realidades que viven nuestros alumnos y alumnas e incansables en la construcción de procesos dinámicos de reflexión y aprendizaje significativo. El libro ofrece un excelente sustento y acervo de materiales para esta encomienda. 